\title{
Remanufacture of hot forging tools and dies using laser metal deposition with powder and a hard-facing alloy Stellite $21^{\circ}$
}

\author{
Jim Foster ${ }^{1}$ (D) $\cdot$ Crawford Cullen $^{1} \cdot$ Stephen Fitzpatrick $^{1} \cdot$ Grant Payne $^{1} \cdot$ Liza Hall $^{1}$ • \\ James Marashi ${ }^{1}$
}

Received: 8 November 2017 / Accepted: 15 October 2018 / Published online: 16 November 2018

(C) The Author(s) 2018, corrected publication 2019

\begin{abstract}
Additive Layer Manufacturing (ALM) processes are attracting interest in the forging industry due to their potential suitability for remanufacturing and repair of tools and dies. The ALM process known as Laser Metal Deposition with powder (LMD- $p$ ) can be used to provide a hard-facing alloy repair to hot forging tools. This is particularly important on complex tool geometries due their superior wear resistance. The Advanced Forming Research Centre (AFRC) has established a low cost standard test method to evaluate abrasive and adhesive wear on hot forging H13 tool steel dies on an industrial scale $160 \mathrm{~kJ}$ Schuler screw press. The bespoke tool design allows researchers to benchmark new and novel coatings, lubricants and additive layers against a known standard. Furthermore, AFRC metrology standard methods ensure repeatability and reproducibility of benchmark results. To evaluate the performance of LMD- $p$ for remanufacturing of hot forging tools and dies, a cobalt based alloy (Stellite $21^{\circledR}$ ) was selected. Stellite $21^{\circledR}$ is widely used as a hard-facing alloy as it provides excellent machinability coupled with superior wear characteristics. AFRC standard dies were coated with LMD- $p$ Stellite $21^{\circledR}$. The LMD- $p$ coating was then machined to final geometry and then subjected to hot forging under AFRC standard conditions to compare to benchmark wear characteristics. Adhesive and abrasive wear was evaluated. It was shown that the Stellite $21^{\circledR}$ LMD- $p$ additive layer performed better in both adhesive and abrasive conditions than standard $\mathrm{H} 13$ tools steel dies.
\end{abstract}

Keywords Remanufacture - Additive layer - Laser metal deposition · Forging · Stellite $21^{\circledR} \cdot \mathrm{H} 13$. Tooling · Dies

Jim Foster

jim.foster@strath.ac.uk

Extended author information available on the last page of the article 


\section{Introduction}

Due to the high costs associated with die replacement and repair, there is a large emphasis across the tool and die sectors (forging, forming, stamping and composite processes) to develop new methods which reduce cost, improve die life, material utilisation and functional performance. Large die sets for super plastic forming fan blades, forging crankshafts and turbine disks can cost $£ 250,000$ and have a significant economic impact on the overall component piece part cost. On average this is approximately $10 \%$ of turnover [1].

The European tool and die market is estimated at $\$ 11$ billion USD per year involving $>7000$ companies [2]. The UK spends around $£ 130$ million manufacturing closed die forging tools and sheet metal dies alone. However, these industries are largely SMEs (90\%) [2] for whom adopting new methods require significant investment.

H13 tool steel is a hot work tool steel that has been the industry standard alloy for forging die applications for a number of years. It has excellent resistance to thermal shock, thermal fatigue, abrasion resistance, and heat resistance $[3,4]$. H13 tool steel provides the necessary requirements to withstand harsh operating environments. Current die remanufacturing practice is to manually inspect for wear and cracking, then flood weld the entire cavity and machine to the desired geometry. There is limited geometric or dimensional verification of cavity features using this method. Dies can also be completely re-machined to remove wear/cracking and recreate their original geometry. Impacts of the current practice include large costs associated with tool steel volumes; weld alloy materials to fill complete cavity and excessive machine cycle times and consumable costs. Additionally, there are significant lead time challenges due to the complex sequence of multi stage unconnected processes involved.

The Additive Layer Manufacturing (ALM) process Laser Metal Deposition (LMD) offers an alternative remanufacturing method for tools and dies. LMD repairs can reduce cost, improve material utilisation and improve functional performance. LMD is an innovative technology that offers significant potential over traditional welding techniques as detailed features can be deposited in specific areas with lower dilution [5]. Furthermore, finer microstructures can be obtained due to fast cooling rates [6] and reduced distortion conditions can be achieved due to lower heat input [7].

Stellite ${ }^{\circledR}$ cobalt based alloys are commonly used in Laser Metal Deposition operations, and in particular, for remanufacturing of components $[8,5,9]$ such as crankshafts [6], shafts [10] and turbine blades [11]. Stellite ${ }^{\circledR}$ alloys exhibit hard facing properties, providing excellent mechanical wear resistance, especially at high temperatures. In addition, they have excellent corrosion, erosion, abrasion, and galling resistance [12]. They also provide good sliding wear resistance [14], which is critical for forging and forming applications. Stellite ${ }^{\circledR}$ alloys and the properties that they exhibit, present significant remanufacturing opportunities to enhance standard H13 tool steel dies.

In order to determine the applicability and functional performance of hard facing Stellite ${ }^{\circledR}$ alloys in forging applications, a practical investigation was undertaken to benchmark standard H13 tool steel dies against a H13 tool steel substrate with an LMD Stellite additive layer.

\section{Aims of research}

The aim of this work was to determine whether the remanufacture of hot forging dies is a feasible and viable option for the forging industry and if so, whether LMD-p provided a suitable repair method. Selected powder based materials were considered as candidates for repair and the relative pros and cons considered. Furthermore, by carrying out forging experiments on an industrial scale screw press and assessing the performance of the repaired dies, confidence in LMD-p repairs 


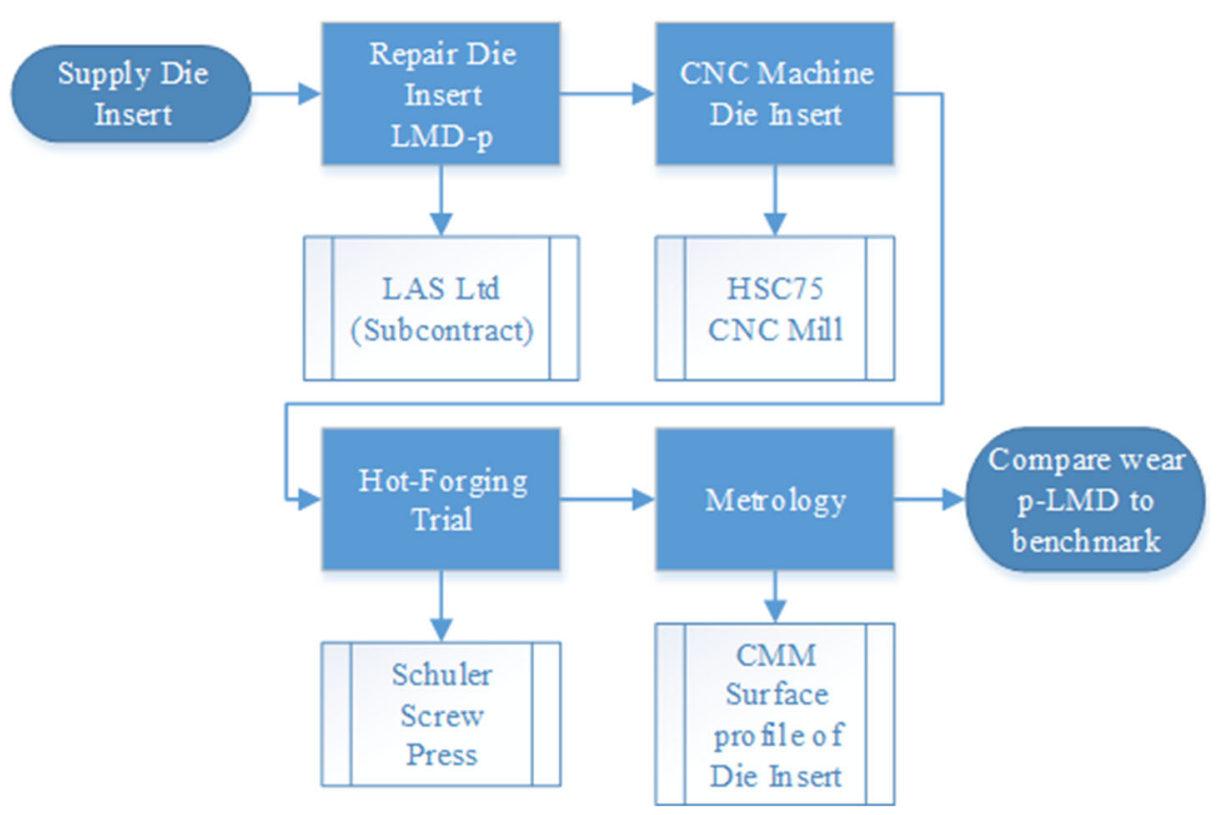

Fig. 1 LMD- $p$ re-manufacturing process

would be enhanced from the perspective of the end user. Finally, due to the selective and precise nature of LMD-p deposition, areas of excessive wear could be targeted to enhance the overall die performance.

\section{Criteria for die repair}

The following criteria were considered with respect to LMD-p as a hot forging die repair methodology.

a. Ease of repair

LMD-p is an ideal candidate for repair of hot forging dies. Laser Metal Deposition equipment and metal powders are readily available and are compatible with selective repair of dies which are exhibiting localised wear.

Table 1 Material Selection decision matrix

\begin{tabular}{lllll}
\hline Materials & $\begin{array}{l}\text { Suitability for } \\
\text { forging conditions }\end{array}$ & $\begin{array}{l}\text { Suitability for } \\
\text { remanufacture }\end{array}$ & $\begin{array}{l}\text { Suitability } \\
\text { for machining }\end{array}$ & $\begin{array}{l}\text { Suitability } \\
\text { for LMD-p }\end{array}$ \\
\hline Stellite 6 & $\checkmark$ & $\checkmark$ & $\checkmark$ & $\checkmark$ \\
Stellite 21 & $\checkmark$ & $\checkmark$ & $\checkmark$ & $\checkmark$ \\
Stainless steel 316 & $\mathrm{X}$ & NA & NA & NA \\
Steel alloy 4340 & X & NA & $\checkmark$ & NA \\
M2 Tool steel & $\checkmark$ & $\checkmark$ & NA & NA \\
COLMONOY ${ }^{\circledR}$ 635 & X & NA & NA & NA \\
Cr3C2-20(Ni 20Cr) & X & NA & $\checkmark$ & $\checkmark$ \\
Inconel ${ }^{\circledR}$ Alloy 718 & $\checkmark$ & $\checkmark$ & $\checkmark$ & $\checkmark$ \\
\hline
\end{tabular}


Table 2 Stellite $21^{\circledR}$ chemical composition

\begin{tabular}{llllll}
\hline Co & Cr & Mo & C & Ni & Other elements present \\
\hline Base & $26-29$ & $4.5-6.0$ & $0.20-0.35$ & $2.0-3.0$ & Fe, Si, Mn \\
\hline
\end{tabular}

\section{b. Machinability}

It is important to ensure that die repair materials can be machined to final geometry with conventional CNC machines and tooling.

\section{c. Wear resistance}

Remanufacturing processes need to return a worn die set to at least the performance levels of the original die set. LMD-p offers the opportunity to select more robust repair materials to, at a minimum, achieve original performance characteristics or indeed exceed wear resistance properties of the original die set. Furthermore, because LMD-p can be deposited in precisely selected areas, there is an opportunity to improve die performance on hitherto areas prone to excessive wear.

\section{d. Hot forging performance}

The in-service performance of remanufactured hot forging dies must, at a minimum, match the original in terms of output and failure modes. LMD-p repaired dies will be assessed by means of the Advanced Forming Research Centre (AFRC) low cost standard test method to benchmark the hot forging performance of die repairs.

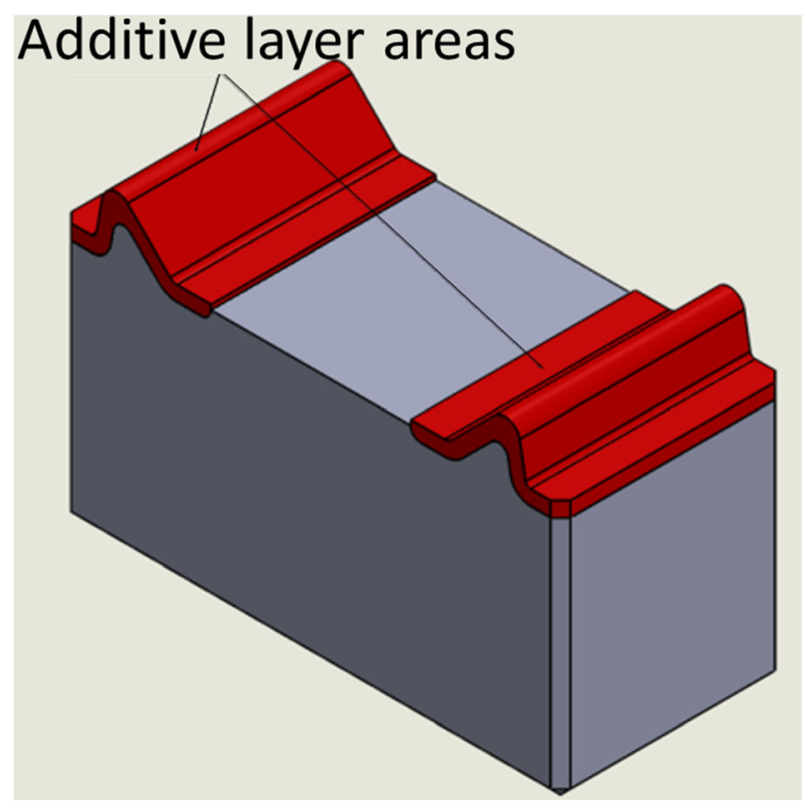

Fig. 2 H13 tool steel die insert with ALM 

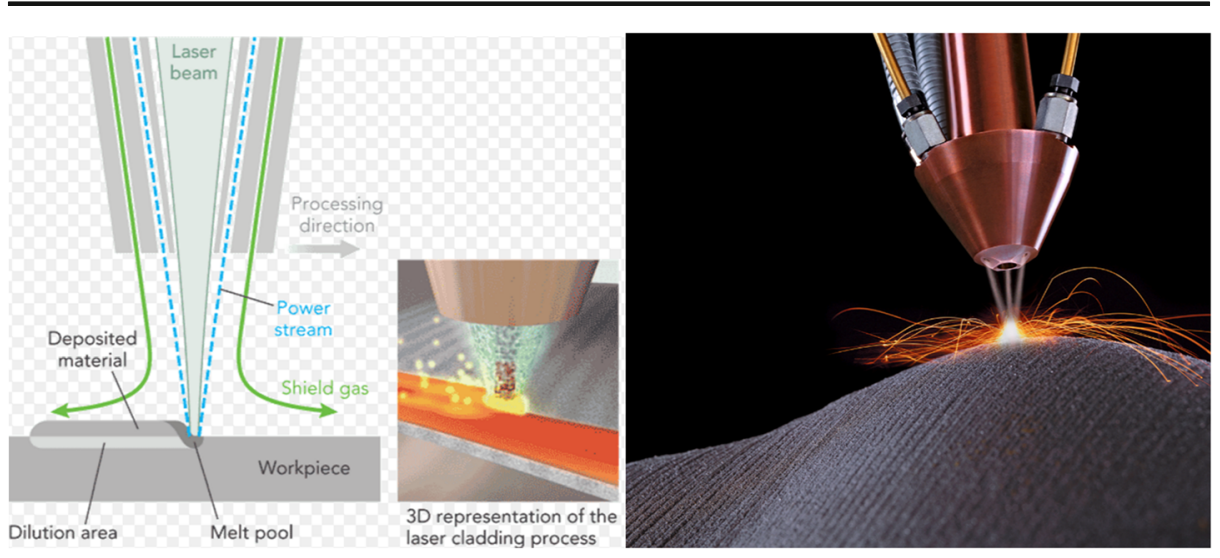

Fig. 3 LMD- $p$ Process

\section{Methods}

\section{Experimental overview}

To investigate the feasibility of using LMD- $p$ Stellite $21^{\circledR}$ as a repair material for tools and dies, a suitable rigorous test of the material was required. AFRC research in the field of forging tool die life provided a unique opportunity to investigate forging die repairs on large industrial scale equipment. Furthermore, re-manufacture utilising AFRC CNC machining capabilities also provided insight into the machinability of the selected repair material. The availability of 'benchmark' wear data allowed direct comparison of the repair material performance in a real life situation. Figure 1 illustrates the re-manufacturing process and subsequent evaluation steps.

Table 3 LMD- $p$ process parameters

\begin{tabular}{lll}
\hline Parameter & Value & Unit \\
\hline Substrate material & H13 Tool Steel & 4Cr5MoSiV1 \\
Deposited material & Stellite 21 & CH4CoCrFeMnMoNiSiW \\
Powder feed rate & $8.2 \%$ & $\mathrm{~g} / \mathrm{min}$ \\
Laser power (PreHeat) & 750 & $\mathrm{~W}$ \\
Laser power (Deposition) & 500 & $\mathrm{~W}$ \\
Radius of defocused laser beam on the substrate (PreHeat) & $8-10$ & $\mathrm{~mm}$ \\
Radius of focused laser beam on the substrate (Deposition) & 1.0 & $\mathrm{~mm}$ \\
Ambient temp & 298 & $\mathrm{~K}$ \\
Melting temp of substrate & 1733 & $\mathrm{~K}$ \\
Melting temp of powder & 1568 & $\mathrm{~K}$ \\
Process speed (PreHeat) & 10 & $\mathrm{~mm} / \mathrm{s}$ \\
Process speed (Deposition) & 12 & $\mathrm{~mm} / \mathrm{s}$ \\
Laser stand off & 12 & $\mathrm{~mm}$ \\
Carrier gas & Argon & $\mathrm{N} / \mathrm{A}$ \\
Shield gas & Argon & $\mathrm{N} / \mathrm{A}$ \\
Step over & 0.5 & $\mathrm{~mm}$ \\
Distance between Nozzle \& Substrate & 12 & $\mathrm{~mm}$ \\
\hline
\end{tabular}


Fig. 4 Typical LMD- $p$ deposit

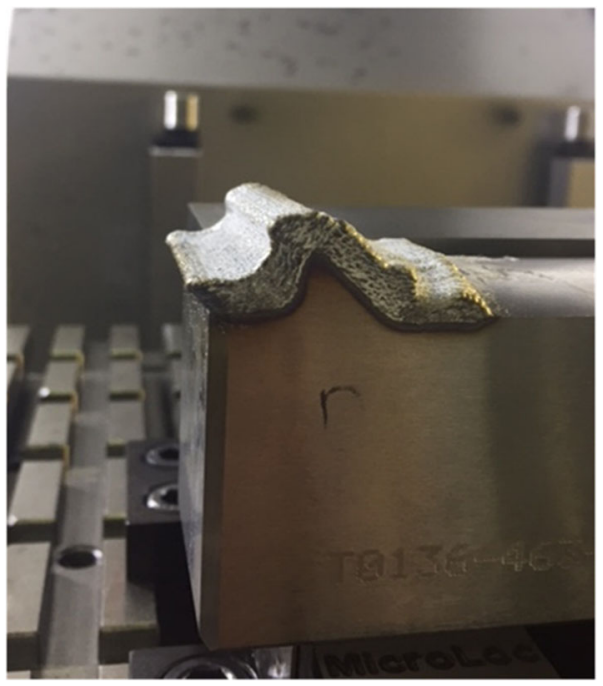

\section{Repair material selection}

Several candidate materials are available for repairing tools and dies using LMD- $p$ additive layer manufacturing. Table 1 illustrates the decision matrix used to select a suitable material for repair of hot forging dies by LMD- $p$. The material selected must also retain adequate machining and forging compatibility for re-manufacturing processes after repair.

Stellite $21^{\circledR}$ was selected as a candidate material as it provided the following characteristics:

- wear resistance - hard facing alloy

- high temperature strength

- resistance to thermal and mechanical shock

- resistance to galling

- metal-to metal sliding wear resistance

- good machining characteristics

The chemical composition (wt.\%) of the cobalt based alloy is shown in Table 2.
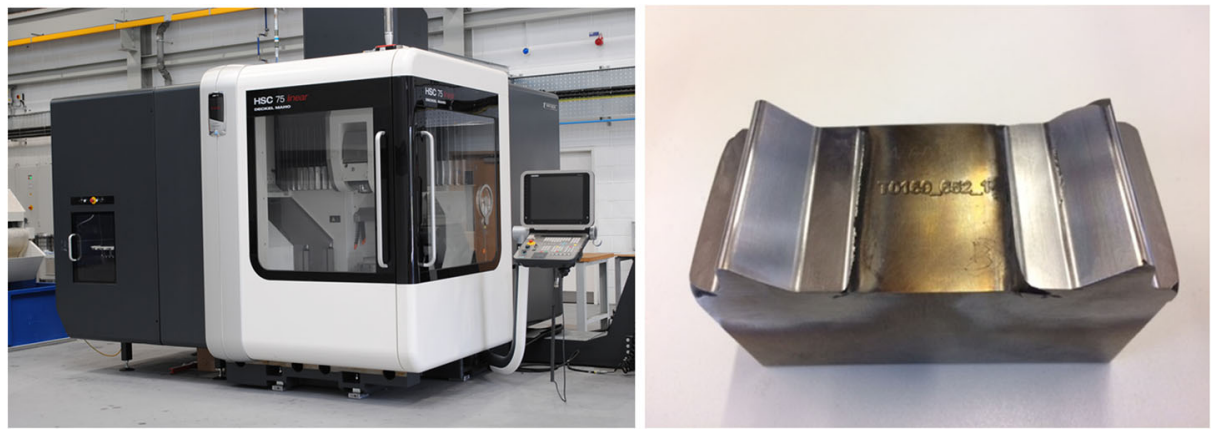

Fig. 5 HSC75 CNC Machining centre and machined die insert 
Table 4 Machining conditions for H13 tool steel and Stellite $21^{\circledR}$

\begin{tabular}{lllll}
\hline & Coolant & Machining strategy & Surface speed $(\mathrm{mm} / \mathrm{min})$ & Feed per tooth \\
\hline H13 Tool Steel & Off & Roughing & 250 & 0.05 \\
H13 Tool Steel & Off & Finishing & 300 & 0.05 \\
Stellite 21 & On & Roughing & 30 & 0.05 \\
Stellite 21 & On & Finishing & 50 & 0.05 \\
\hline
\end{tabular}

\section{Die insert selection}

Tools and dies can be very expensive to produce and their complex geometry can make evaluation of repairs difficult. However, AFRC has developed a hot-forging standard test method which is low cost to perform and provides benchmark data to allow direct comparison of ALM materials. Figure 2 illustrates the AFRC standard low cost die insert and Stellite $21^{\circledR}$ ALM material is shown in red. The die insert is mirrored around its centre to maximise material utilisation providing two forging trials per die insert. Cylindrical billets are forged on the peak of the die insert (see section 6 for more detail).

The die insert is manufactured from H13 tool steel at Rockwell hardness (HRC) 52-54 and is $100 \mathrm{~mm} \times 45 \mathrm{~mm} \times 60 \mathrm{~mm}$ in dimension with $2 \mathrm{~mm}$ radius peak.

\section{Powder laser metal deposition (LMD-p) repair}

LMD- $p$ is an additive layer manufacturing (ALM) technique wherein a metal powder is conveyed through a nozzle onto a metal substrate. A laser is used to melt a layer of powder into the desired shape along CNC toolpaths (Fig. 3).

The process is repeated layer by layer to create a solid three dimensional geometry on the substrate. The laser power required to produce the desired melt pool is in the range $0.5 \mathrm{~kW} \sim$ $2.0 \mathrm{~kW}$ which, on solidification, results in a fine grain microstructure due to high cooling rate $\left(105 \mathrm{Ks}^{-1}\right)$. LMD- $p$ produces a metallurgical 'fusion' bond with the substrate of density $>99.5$ and typical layer thickness of $0.2 \mathrm{~mm}$ to $2.5 \mathrm{~mm}$. Distortion is minimised due to the small Heat Affected Zone (HAZ) of the laser with $<5 \%$ dilution of the substrate. LMD- $p$ was subcontracted to LAS Ltd., Doncaster, England with the requirement to deposit a minimum of $5 \mathrm{~mm}$ Stellite $21^{\circledR}$ onto the H13 tool steel substrate. Table 3 details LMD- $p$ process parameters.

Figure 4 shows a typical AFRC die insert repaired with $5 \mathrm{~mm}$ LMD-p deposited Stellite $21^{\circledR}$.

\section{Machining of repaired die insert}

LMD- $p$ repaired die inserts were machined to obtain the original die insert geometry on a DMG Mori HSC75 CNC machining centre as shown in Fig. 5.

Table 5 H13 tool steel chemical composition

\begin{tabular}{lllllll}
\hline & $\mathrm{C}$ & $\mathrm{Si}$ & $\mathrm{Mn}$ & $\mathrm{Cr}$ & $\mathrm{Mo}$ & $\mathrm{V}$ \\
\hline Typical $(\%)$ & 0.39 & 1.03 & 0.45 & 5.30 & 1.28 & 0.95 \\
\hline
\end{tabular}




\section{Die Insert}

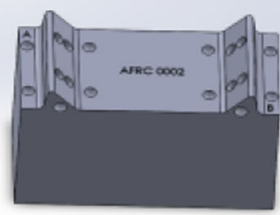

H13 Tool Steel

- HRC 52-54

- Fillet/notch geometry

- Impart shear stress

- Low cost
Die Assembly

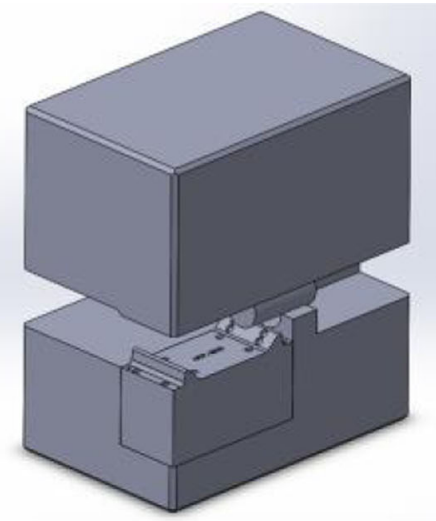

Billet

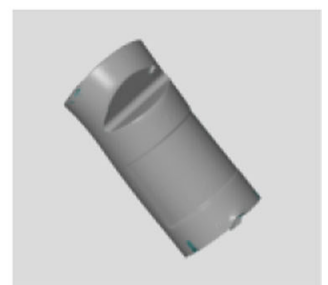

Cylindrical billets

- Aluminium - soft, no wear

- 316 stainless steel - low wear

- 321 stainless steel - low wear

- Inconel 718 - high wear

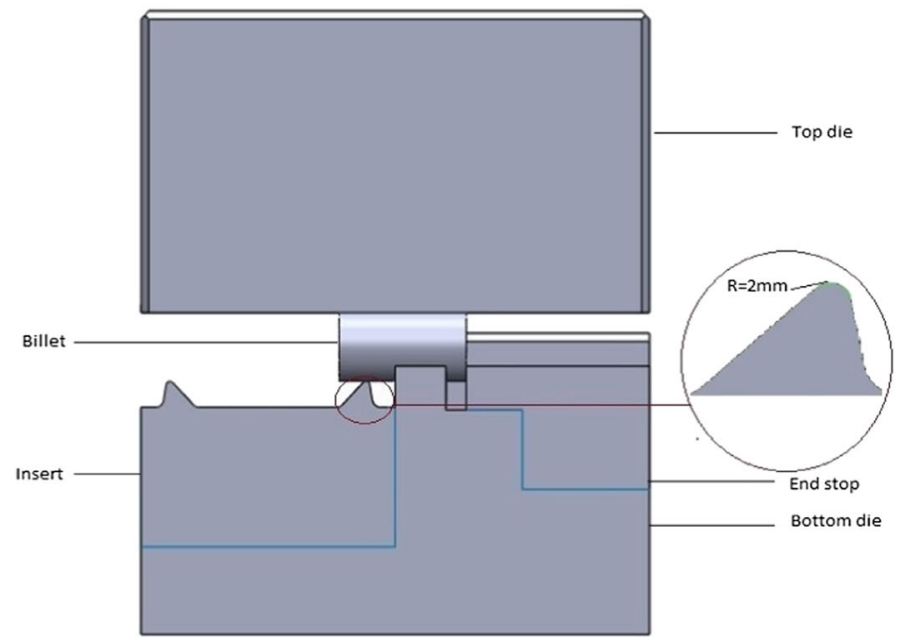

Fig. 6 AFRC die set

When compared to $\mathrm{H} 13$ tool steel, modified machining parameters were required for Stellite $21^{\circledR}$ and are detailed in Table 4.

\section{Hot forging standard test method}

The Advanced Forming Research Centre (AFRC) has established a low cost standard test method to evaluate abrasive and adhesive wear [13] on H13 tool steel dies for hot forging applications. H13 tool steel [16] is a chromium-molybdenum-vanadium alloyed steel used in the manufacture of hot forging tools and dies (Table 5).

H13 tool steel provides durability, strength, corrosion resistance and high-temperature stability in service. The bespoke tool design allows researchers to benchmark new and novel coatings, lubricants and additive layers against a known data standard and allows researchers to assess the performance of the new processes and materials in terms of abrasive and adhesive wear. The fillet radius $(2 \mathrm{~mm})$ has been carefully selected to ensure 
Fig. 7 Schuler screw press

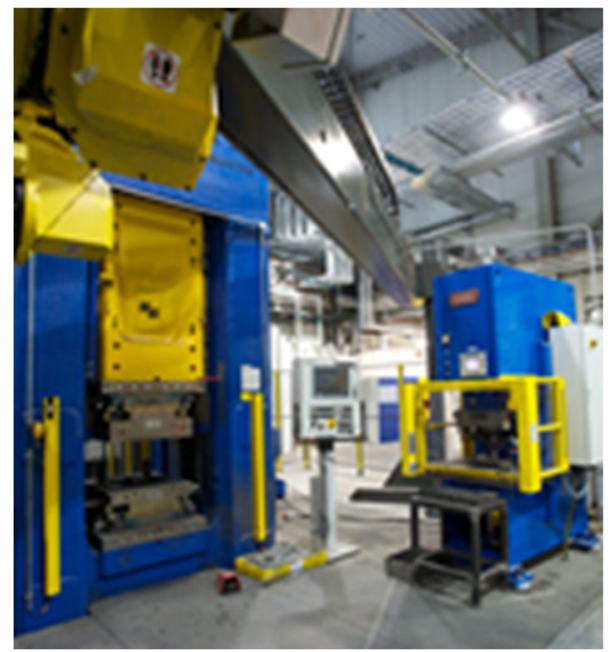

that surface changes on the die insert are attributable to abrasive and adhesive wear. This geometry eliminates plastic deformation of the die insert [13].

The selection of the metal billets to be forged is also a significant factor to be considered. Several metals were assessed for suitability in providing measureable wear characteristics at sufficiently low number of forging cycles to keep costs at a minimum. Inconel 718, whilst the most expensive metal to purchase, was found to provide measureable wear after only 25 forging cycles and was selected as the benchmark. Figure 6 illustrates the bespoke die set used in the hot forge.

Forging trials were carried out on an industrial scale $160 \mathrm{~kJ}$ Schuler screw press (Fig. 7).

The forging process is shown in Fig. 8.

The forging cycle consists of heating Inconel 718 billets to their forging temperature of $1050 \mathrm{C}$ for $15 \mathrm{~min}$. The top and bottom die temperature is set at $250 \mathrm{C}$ and $230 \mathrm{C}$ respectively and coated in aqueous graphite lubricant (10\% wt. carbon). The hot billets are then transferred to the forge where the top die is driven to impact each billet in turn at $10 \%$ $(16 \mathrm{~kJ})$ energy. The $2 \mathrm{~mm}$ fillet on the die insert produces a notch on the billet and die insert is subjected to wear on the surface due to sliding together of metal surfaces. The cylindrical billet $(25 \mathrm{~mm} \phi \times 50 \mathrm{~mm})$ is notched as shown in Fig. 6 .

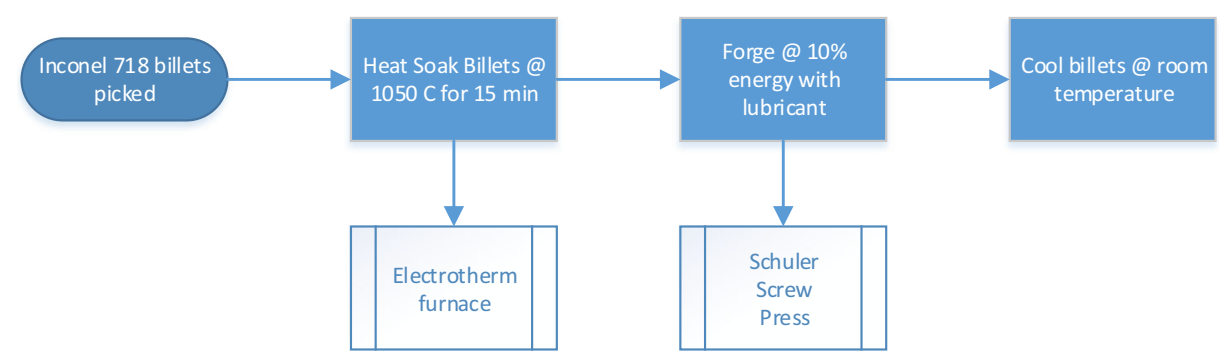

Fig. 8 Forging process 


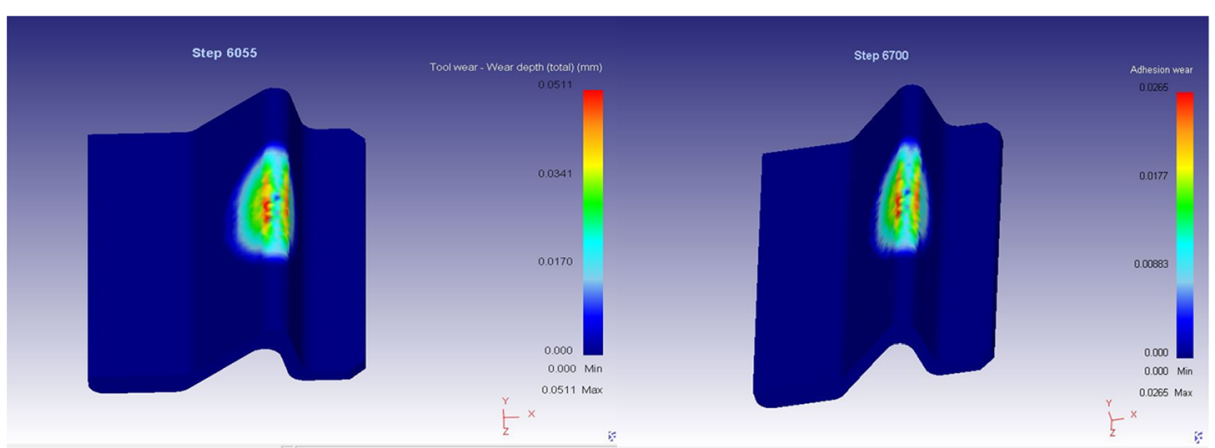

Fig. 9 Predicted abrasive/adhesive wear

\section{Hot forging process simulation}

AFRC has modelled [14] the forging process for H13 tool steel/Inconel 718 in DeFORM ${ }^{\circledR}$ modelling software to predict abrasive and adhesive wear. The standard model was adapted to include the addition of a layer of Stellite ${ }^{\circledR} 21$ repair on the surface of the die insert to validate the practical experimental trial. Figure 9 shows the predicted abrasive and adhesive wear after 25 forging cycles.

The simulation model predicts $51 \mu \mathrm{m}$ abrasive wear and $26 \mu \mathrm{m}$ respectively.

\section{Metrology}

AFRC Metrology standard methods were developed to ensure repeatability and reproducibility of benchmark results. Measurements are carried out on a Coordinate Measurement Machine (CMM) using a $0.7 \mathrm{~mm}$ ruby probe to produce surface profile scans of the die insert. CMM profiling is carried out on both pre-forging die inserts and post-forging die inserts. A fine step over of $0.1 \mathrm{~mm}$ is used to maximise data points and individual scans are meshed together to
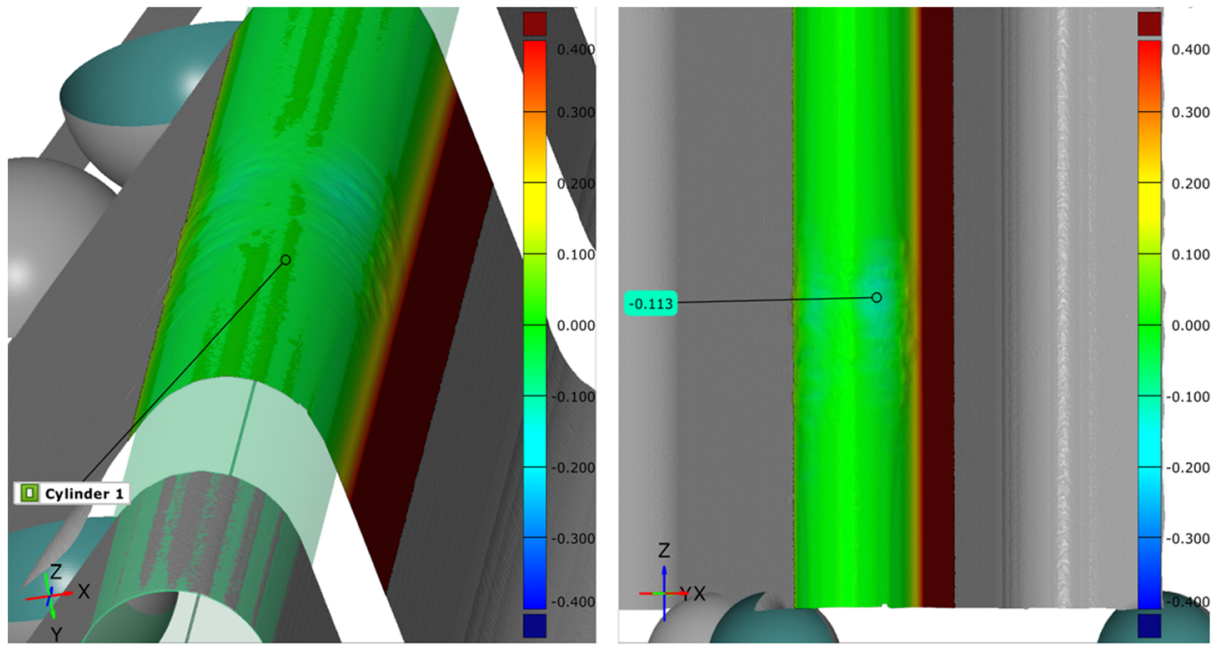

Units in $\mathbf{m m}$

Fig. $10 \mathrm{CMM}$ surface profiling 


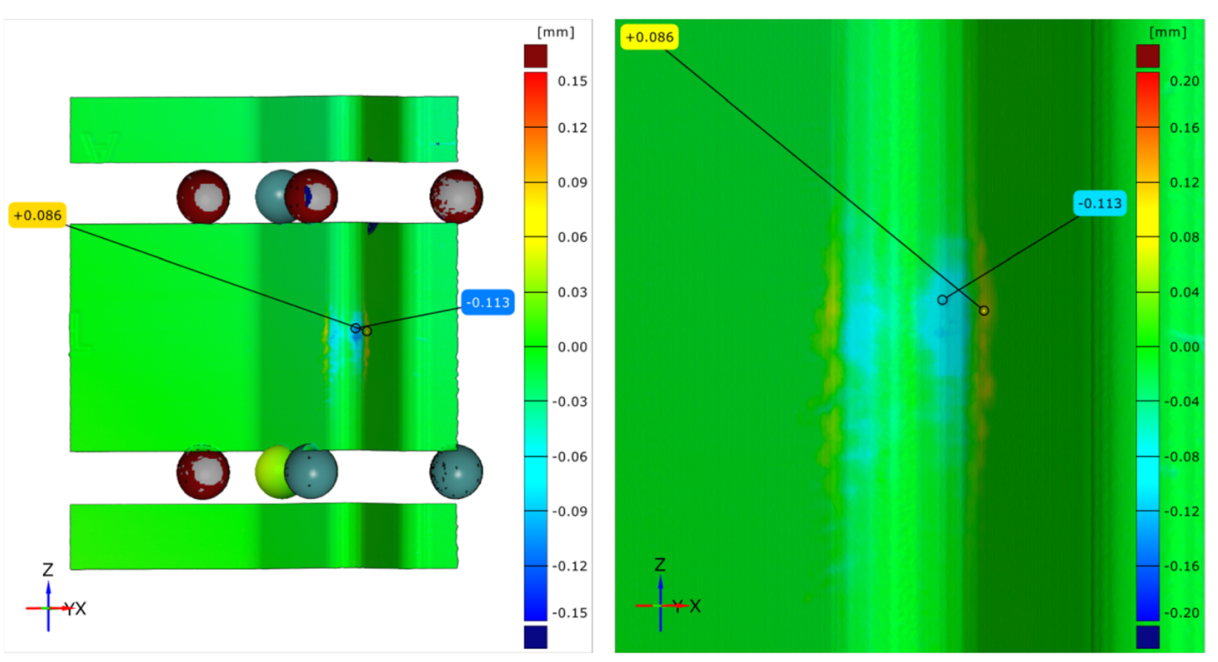

Fig. 11 CMM surface profile for H13 tool steel die insert benchmark

create a surface profile. Finally, surface scans are aligned using a cylindrical deviation technique to determine wear values. A typical surface scan is shown in Fig. 10.

\section{Results}

\section{Wear comparison}

To evaluate the performance and suitability of Stellite $21^{\circledR}$ as a repair material for tools and dies, wear is considered as the primary failure mode to be investigated. Wear, in microns $(\mu \mathrm{m})$, was measured for a LMD- $p$ repaired die insert and compared against $\mathrm{H} 13$ tool steel original die insert using available benchmark data. Abrasive wear areas, corresponding to metal removal,
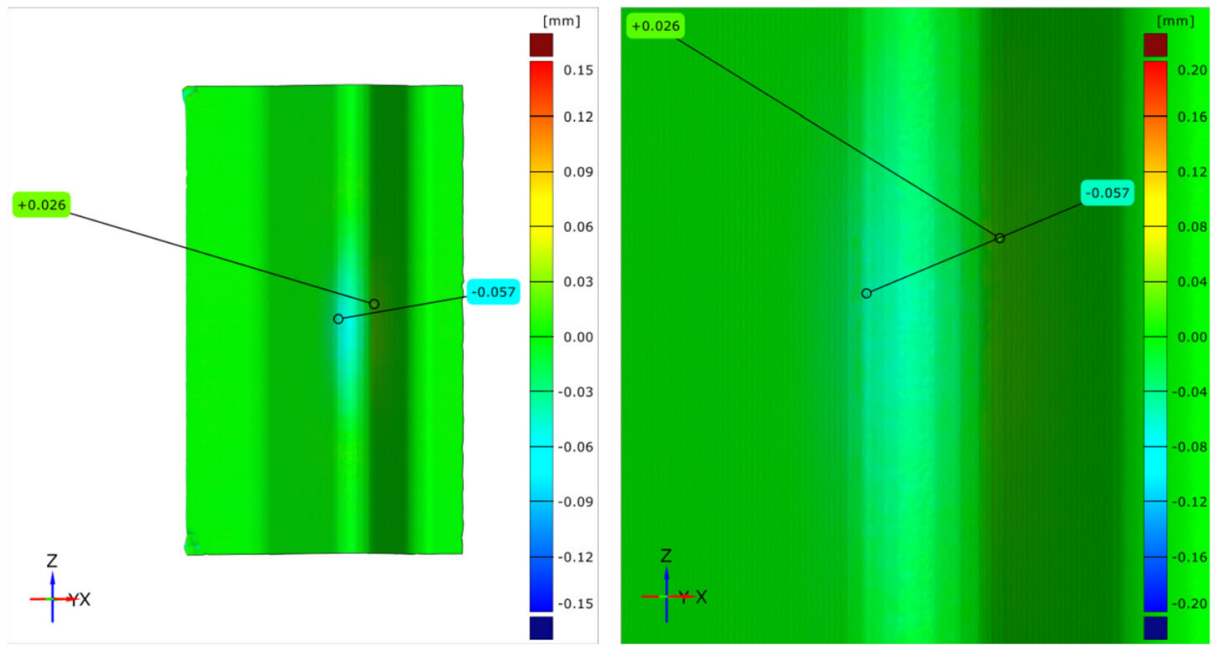

Fig. 12 CMM surface profile for LMD-p repaired die insert 
Table 6 Improvement of abrasive wear using LMD- $p$ Stellite $21^{\circledR}$

\begin{tabular}{llll}
\hline Die insert & $\begin{array}{l}\text { Abrasive } \\
\text { wear }(\mu \mathrm{m})\end{array}$ & $\Delta \mathrm{v}$. benchmark $(\mu \mathrm{m})$ & $\%$ improvement \\
\hline H13 & 0.108 & & 49 \\
LMD-p & 0.055 & 0.053 & 49 \\
\hline
\end{tabular}

are denoted by a negative value and areas of adhesive wear, corresponding to metal accumulation, are denoted by a positive value. Figure 11 illustrates the surface profile for a H13 tool steel die insert after 25 forging cycles.

Figure 12 illustrates the surface profile of a LMD- $p$ repaired die insert after 25 forging cycles under corresponding benchmark process conditions.

Table 6 compares the performance, in terms of maximum abrasive wear, of a LMD- $p$ repaired die insert with corresponding benchmark data.

Table 7 compares the performance, in terms of maximum adhesive wear, of a LMD- $p$ repaired die insert with corresponding benchmark data.

\section{Microstructural analysis}

When considering the suitability of Stellite $21^{\circledR}$ as a repair material for tools and dies, the microstructure of the deposition layer must be considered. Figure 13 illustrates a typical repaired area of the die insert.

\section{Discussion}

The aim of this work was to determine the suitability of LMD- $p$ as a repair method for hot forging tools and dies based on the following criteria:

\section{Ease of repair}

The LMD- $p$ process was ideally suited to repairing die inserts. The powder alloy is readily available as is the laser deposition equipment. Alloys can easily be deposited on a typical tool steel substrate.

\section{Machinability}

CNC machining of repaired die inserts require changes to process parameters for best results (Table 4). To ensure adequate milling to the original geometry, coolant was

Table 7 Improvement of adhesive wear using LMD- $p$ Stellite $21^{\circledR}$

\begin{tabular}{llll}
\hline Die insert & $\begin{array}{l}\text { Adhesive } \\
\text { wear }(\mu \mathrm{m})\end{array}$ & $\begin{array}{l}\Delta \mathrm{v} \text {. benchmark } \\
(\mu \mathrm{m})\end{array}$ & $\%$ improvement \\
\hline H13 & 0.082 & & 67 \\
LMD-p & 0.027 & 0.055 & 67 \\
\hline
\end{tabular}



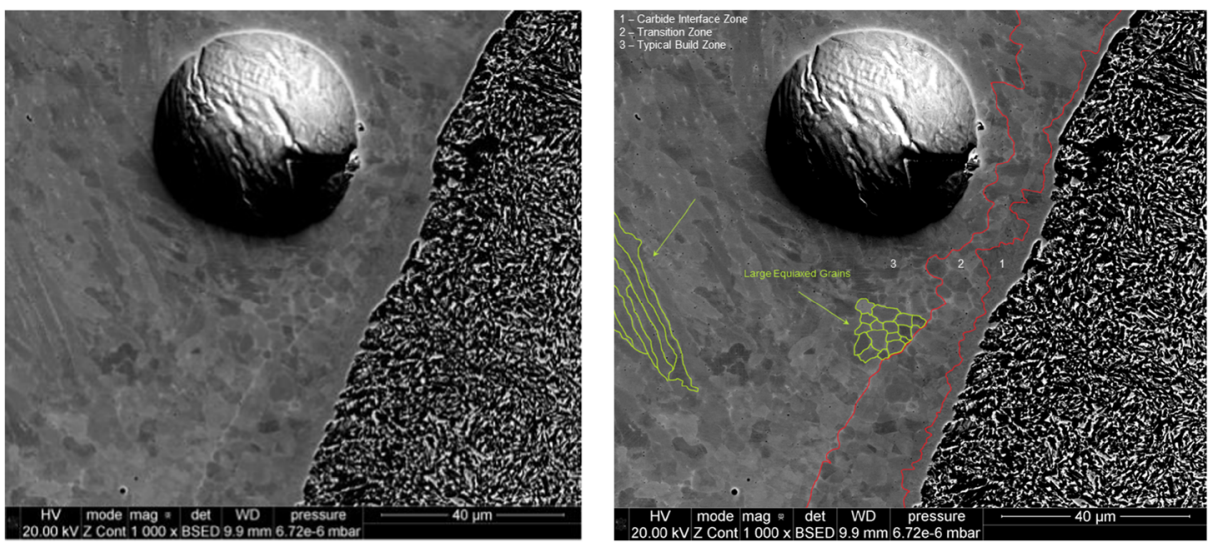

Fig. 13 Stellite $21^{\circledR}$ to $\mathrm{H} 13$ interface microstructure

essential and a reduction in surface speed was required to minimise tool wear and produce an acceptable surface finish. Therefore, from a technical perspective, machinability of the repair is excellent but increased costs in terms of materials and productivity should be considered.

\section{Wear resistance}

Wear resistance of the selected repair material is critical with respect to tool and die performance as detailed by Summerville et al. [1]. Stellite $21^{\circledR}$ provided an overall improvement in wear characteristics when compared to AFRC benchmark figs. [14].

Abrasive wear was improved by $49 \%$ and adhesive wear was improved by $67 \%$ over AFRC forging benchmark data [14]. Simulation of the forging process predicted abrasive wear of $51 \mu \mathrm{m}$ which correlated well with $55 \mu \mathrm{m}$ obtained via physical trial. Adhesive wear was also accurate in prediction, $26 \mu \mathrm{m}$ compared to $27 \mu \mathrm{m}$.

With respect to abrasive wear, Stellite ${ }^{\circledR}$ alloys exhibit hard-facing properties and provide excellent mechanical wear resistance, especially at high temperatures. In addition, they have excellent corrosion, erosion, abrasion, and galling resistance [12]. These alloys also provide resistance to sliding wear [14]. All of these attributes are essential for hot forging applications. Furthermore, Diaz et al. [5] found cobalt based alloys were ideal candidates for LMD-p repair applications. The combination of wear resistance and ease of repair show that LMD- $p$ repairs using Stellite $21^{\circledR}$ should result in significant improvement in terms of all aspects of wear experienced during hot forging. Experimental data from AFRC trials correlate well with expectations for abrasive wear and confirm the suitability of Stellite $21^{\circledR}$ for hot forging die repair.

Adhesive wear improvements were also significant. H13 tool steel dies are heated to 200-250 ${ }^{\circ} \mathrm{C}$ during the forging operation $[13,14]$. There is a reduction in tensile strength of $\mathrm{H} 13$ tool steel at these temperatures [15]. However, Stellite $21^{\circledR}$ maintains its tensile properties within this temperature range [16]. Therefore, H13 tool steel dies will retain more Inconel 718 from the forged billet on their surface than repaired Stellite $21^{\circledR}$ dies. The result is increased die life. 


\section{Hot forging performance}

Repaired die inserts performed better in hot forging conditions when compared to the benchmark process [14]. Less wear was detected and improved handling of billets was observed due to a reduction in adhesion. Removal of forged products from tools and dies is very important. Components can stick to the die and sometimes additional ejectors are required to help eject forged material. However, with the reduction in adhesive wear, billets are easier to remove from the die insert post forging. The result is improved die life and ease of production of forged parts. This is a similar experience as shown by Brandt et al. [11].

Furthermore, die inserts show little degradation when compared to H13 tool steel die inserts. The microstructural analysis would suggest the presence of gas voids and potential for micro-cracking in columnar lamellar grains due to high cooling rates. These issues could possibly result in tool and die defects. Die design is important when considering repair geometry and avoidance of plastic deformation, as found by Marashi et al. [13], is important. Consideration of microstructural aspects of the metallurgy of such repairs in future experiments would be prudent.

\section{Conclusions}

Based on process observations and the results obtained, LMD- $p$ is a suitable candidate for consideration in repairing hot forging tools and dies. Furthermore, Stellite $21^{\circledR}$ appears to offer excellent wear resistance, toughness, machinability and forge-ability in the application studied and would be an alloy worthy of further investigation for use in complex die repair.

Acknowledgements The technical assistance given by Mr. Peter Brown of LAS Limited, Doncaster, England for LMD-p processes is very much appreciated.

The work contained within this paper was supported by the High Value Manufacturing (HMV) Catapult, The Oracle Building, Blythe Valley Business Park, Shirley, Solihull, B90 8 AD which was established by Innovate UK through grant 160051, at the Advanced Forming Research Centre, University of Strathclyde, 85 Inchinnan Drive, Renfrewshire, PA4 9LJ, United Kingdom.

Open Access This article is distributed under the terms of the Creative Commons Attribution 4.0 International License (http://creativecommons.org/licenses/by/4.0/), which permits unrestricted use, distribution, and reproduction in any medium, provided you give appropriate credit to the original author(s) and the source, provide a link to the Creative Commons license, and indicate if changes were made.

\section{References}

1. Summerville E, Venkatesan K, Subramanian C (1995) Wear processes in hot forging press tools. Mater Des 16(5):289-294

2. platform, e.t. european tooling platform. Available from: http://toolingplatform.manufuturenet.eu/index. php/european-tooling-platform

3. Maeda K, Childs THC (2004) Laser sintering (SLS) of hard metal powders for abrasion resistant coatings. J Mater Process Technol 149(1-3):609-615

4. Shin, H., et al. The surface heat treatment of die steel SKD61 using CW Nd: YAG laser. in Proceeding of KSME 2006 Spring Annual Meeting 2006

5. Díaz E, Amado JM, Montero J, Tobar MJ, Yáñez A (2012) Comparative study of co-based alloys in repairing low Cr-Mo steel components by laser cladding. Phys Procedia 39:368-375 
6. Piasecki A et al (2013) Laser cladding of Stellite 6 on low carbon steel for repairing components in automotive applications using disk laser. Archives of Mechanical Technology and Automation 33(2):25-34

7. Heigel J, Michaleris P, Palmer T (2015) In situ monitoring and characterization of distortion during laser cladding of Inconel® 625. J Mater Process Technol 220:135-145

8. Díaz E, Tobar MJ, Yáñez A, García J, Taibo J (2010) Laser powder welding with a co-based alloy for repairing steam circuit components in thermal power stations. Phys Procedia 5:349-358

9. Graf B, Gumenyuk A, Rethmeier M (2012) Laser metal deposition as repair technology for stainless steel and titanium alloys. Phys Procedia 39:376-381

10. Andolfi, A., et al., Advanced laser cladding application for oil and gas components. GE Oil \& Gas Newsletter (General Electric Company, Fairfield, CT, 2012), 2012: p. 164-173

11. Brandt M, Sun S, Alam N, Bendeich P, Bishop A (2009) Laser cladding repair of turbine blades in power plants: from research to commercialisation. International Heat Treatment and Surface Engineering 3(3):105-114

12. Kennametal. Hardfacing Alloys Brochure. Available from: https://www.kennametal. $\mathrm{com} / \mathrm{content} / \mathrm{dam} / \mathrm{kennametal} / \mathrm{kennametal} / \mathrm{common} /$ Resources/Catalogs-Literature/Industry $\% 20$ Solutions/B-16-05107_KMT_Stellite_HardfacingAlloys_Brochure_EN_LR.pdf [12]

13. Marashi J, Yakushina E, Xïrouchakis P, Zante R, Foster J (2017) An evaluation of H13 tool steel deformation in hot forging conditions. J Mater Process Technol 246:276-284

14. Marashi, J., et al. Defining a method of evaluating die life performance by using finite element models (FEM) and a practical open die hot forging method. In AIP Conference Proceedings. 2016. AIP Publishing

15. Uddenholm. H13 data sheet. Available from: http://www.bucorp.com/media/H13 data sheet_09032013.pdf

16. Solutions, D.W. Stellite 21 alloy. Available from: https://static1.squarespace.com/static/56e $079802 \mathrm{fe} 131546$ a70830d/t/588a1e7f197aea571f37a590/1485446785712/Deloro+MDS+Stellite21+rev00.pdf

Publisher's note Springer Nature remains neutral with regard to jurisdictional claims in published maps and institutional affiliations.

\section{Affiliations}

\section{Jim Foster ${ }^{1} \cdot$ Crawford Cullen $^{1} \cdot$ Stephen Fitzpatrick $^{1} \cdot$ Grant Payne $^{1} \cdot$ Liza Hall $^{1}$ • James Marashi ${ }^{1}$}

Crawford Cullen

crawford.cullen@strath.ac.uk

Stephen Fitzpatrick

s.fitzpatrick@strath.ac.uk

Grant Payne

grant.payne@strath.ac.uk

Liza Hall

liza.hall@strath.ac.uk

James Marashi

james.marashi@strath.ac.uk

1 Advanced Forming Research Centre, University of Strathclyde, 85 Inchinnan Drive, Glasgow, UK 